\title{
CO-CREATION IN A SERVICE INNOVATION CONTEXT
}

\author{
Shikha Sharma, University of Adelaide, Australia \\ Jodie Conduit, University of Adelaide, Australia \\ Ingo Oswald Karpen, RMIT University, Australia \\ Sally Rao Hill, University of Adelaide, Australia \\ Francis Farrelly, RMIT University, Australia
}

\begin{abstract}
In the recent past, research on innovation was primarily concerned with processes which were initiated, executed and managed by the provider themselves. Unique skills were developed internally by the organizations and kept secret from the market until launch (Chesbrough 2003). More recently, organizations have realized the importance of collaborating with other actors to advance their capabilities and innovation competencies (Camarinha-Matos 2009; Chen, Tsou and Ching 2011). Current approaches to innovation embrace a multi-actor approach and a paradigm shift has occurred from closed innovation to collaborative and open innovation (Greer and Lei 2012). Aligned with Prahalad and Ramaswamy's (2000) concept of 'co-creation', scholars have started to examine the collaborative role of customers in innovation. While there has been a focus in past on integrating lead users into the innovation process (e.g. von Hippel 1986; Herstatt and von Hippel 1992), more research is needed on general customer innovation and community innovation contributions, particularly in a service context. Attention has accordingly shifted from the tangible aspects of product innovation to the co-produced innovation process and the co-created value between an organization and its customers. Understanding how this notion can be harnessed for the purposes of innovating service and service solutions, is a current managerial and academic challenge (Ordanini and Parasuraman 2011). This paper addresses calls for a greater understanding of the involvement of customers in service innovation and argues for collaborative behaviors to drive service innovation performance. The specific behaviors exhibited by customers in this process will be investigated by way of the proposed co-creation construct and its behavioral manifestations (Yi and Gong 2012).
\end{abstract}

Although customer participation in and contribution to the service innovation experience has been advocated for many years (Greer and Lei 2012), the collaborative behaviors are not well understood (Alam 2011; Ngo and O'Cass 2012). The collaborative process itself is recognized to require learning and knowledge transfer (Ordanini and Parasuraman 2011; Ojanen and Hallikas 2009; Payne et al. 2008), lead user collaboration (von Hippel 2005), participative design (Buur and Matthews 2008), transformational leadership (O'Cass and Sok 2012) and the presence of trust and empathy (Etgar 2008). Etgar (2008) describes co-production as customers participating in the performance of various activities within the production process; however despite this focus, there is no framework explicating the co-production behaviors exhibited by customers during this process. Nonetheless, Yi and Gong (2012) recently introduced a set of 'Customer Value Co-Creation Behaviors', which might also serve the purpose of collaborative service innovation. Yi and Gong (2012) conceptualized and operationalized customer value co-creation behaviors by way of eight dimensions: information seeking, information sharing, responsible behavior, personal interaction, feedback, advocacy, helping, and tolerance. Modeled as a third-order customer value co-creation construct, the first four of these dimensions are linked to a second-order Customer Participation Behavior construct, whereas the remaining four dimensions are part of a second-order Customer Citizenship Behavior construct. While these co-creation behaviors are believed to be generically relevant in co-constructing meaningful experiences, the question is how far these behaviors are also relevant in a service innovation context.

This paper argues that both Customer Participation Behavior and Customer Citizenship Behaviors play an essential role in effective and efficient joint service innovation processes. This paper contributes by providing a perspective on the behaviors required to facilitate service innovation. It takes each of the co-creation behaviors proposed by Yi and Gong (2012) and demonstrates their potential influence on collaborative service innovation. This significantly fosters our understanding of the process of co-innovation and its potential contribution to service innovation performance. We also present a set of research propositions that align customer co-innovation activities with relevant outcomes in a nomological network. Ultimately, higher levels of co-creative behaviors proposed by Yi and Gong (2012) are expected to lead to higher service innovation performance. However, the link between these constructs and potential contingency factors has not been studied empirically in a consumer context and needs to be investigated and validated.

References available upon request 